\title{
Aprender a desaprender no processo de criação do espetáculo ${ }^{I}$
}

Gisele Lamb ${ }^{2}$

\section{Resumo}

Diante de diversos espetáculos de teatro de bonecos manipulados à vista assistidos, surgiu a inquietação com relação ao que confere a alguns deles qualidade técnica e artística. Constatei que a criação e adoção de partitura de movimentos é uma técnica de grande importância para que se atinja tal qualidade. Mas como percorrer o caminho da técnica sem que com isso se perca de vista a poética? A proposta do presente artigo é oferecer ao atorcriador de espetáculo de teatro de animação uma imagem que o auxilie em seu percurso de criação, através de uma metáfora de tal processo como a recuperação do mito do paraíso perdido. Nesta perspectiva, a etapa de improvisação equivaleria ao paraíso, em um estado no qual prevalece a graça e a inocência. Mas como a inocência carrega em si sua própria transgressão, a queda, entendida como a separação entre homem e natureza, pela tomada de consciência, é apresentada como a adoção da técnica, que, enquanto é aprendida, limita o artista. Caberia então ao homem uma ascensão ao paraíso, o que não pode acontecer pela negação da consciência, mas, sim, pelo reconhecimento e superação de seus limites, até um estado em que a ação humana seja governada pelo sentimento. Na metáfora proposta, tal conquista acontece quando o ator, após muito treino e repetição, incorpora de tal forma a técnica, que a desaprende.

Palavras-chave: improvisação - partitura de movimentos - criação do espetáculo

O essencial é saber ver.

Saber ver sem estar a pensar,

Saber ver quando se vê,

Enem pensar quando se vê

Nem ver quando se pensa.

Mas isso (tristes de nós que trazemos a alma vestida!),

\footnotetext{
${ }^{1}$ Artigo publicado no livro Teatro de Bonecos: distintos olhares sobre a teoria e a prática

${ }^{2}$ Graduanda do curso Bacharelado em Artes Plásticas - CEART/UDESC, integrante da pesquisa Transformações na poética da linguagem do Teatro de Animação, coordenada pelo Prof. Dr. Valmor Nini Beltrame
} 
Isso exige um estudo profundo, Uma aprendizagem de desaprender.

\section{Fernando Pessoa}

As idéias sobre as quais discorro a seguir surgiram a partir da inquietação provocada diante de diversos espetáculos assistidos nos quais os bonecos eram manipulados à vista. Por vezes os manipuladores se mostravam livres e inteiros em seu labor, enquanto os bonecos pareciam c a gir por vontade própria. Por outras, o títere mantinha sua qualidade de objeto, pedaço de matéria inerte, contra a qual o manipulador parecia lutar.

Como se conquista um trabalho de categoria técnica e artística? Qual a diferença de procedimento por trás dessa diferença nos resultados?

Primeiramente constatei que a relação estabelecida entre animador e boneco, mesmo quando à vista, pode se dar de diversas formas, tal como ensina Michael Meschke. Mas a qualidade da animação não depende disso, já que o tipo de relação estabelecida acaba por configurar um elemento dramatúrgico ou constitutivo do personagem. $\mathrm{O}$ ator pode estar oculto; assumir seu papel de manipulador como uma função representativa própria, seja como aquele dá vida ao boneco, seja como seu duplo ou alter-ego; ou ainda representar um personagem, uma contra-parte do boneco (MESCHKE, 1988, p.31,32 e 35), e, independente de qual for a escolha, provocar aquilo que Henrik Jurkowski chama de sinergia: a interação entre o ator e o boneco.

Mas se a diferença não está no tipo de relação estabelecida, onde reside ela? Ao conversar com alguns dos artistas a cujos espetáculos assisti, constatei que a criação e adoção de partitura de gestos é um dos elementos que faz diferença no processo de criação e no resultado do espetáculo. Arriscaria dizer inclusive que se faz essencial, apesar de não ser, é claro, uma fórmula mágica.

Aceitando tal pressuposto, e buscando entender como se desenvolve a partitura, e como a partir dela o resultado pode ou não ser o desejado, me deparei com o texto de Arroyave $^{3}$, no qual faz uma leitura filosófica do artigo Sobre o teatro de marionetes, de

${ }^{3}$ La conciencia y la gracia - Una interpretacion filosófica de Sobre el teatro de marionetas de Henrich von Kleist. 
Henrich Kleist. Apesar de o texto não tratar do processo de criação de um espetáculo, tampouco da preparação do ator, intuí que ali estava ilustrado um possível percurso a ser seguido.

Assim, sem a pretensão de propor algum método ou respostas definitivas, busco neste texto oferecer uma imagem que auxilie no percurso de criação do espetáculo.

\section{A expulsão do paraíso}

Henrich von Kleist apresenta o diálogo entre dois personagens cujo tema central é a graça e a consciência. Aquela entendida como um "estado natural da existência humana, no qual o homem mantém sua unidade com o mundo" (ARROYAVE, 2001, p.43), perdida quando, expulso do paraíso, ele abriu os olhos e experimentou a vergonha pela própria nudez, e a culpa por ter contrariado a vontade divina. Segundo Arroyave, a expulsão do paraíso alude à perda daquela unidade com o surgimento da idéia de bem e mal, eu e o outro.

É interessante observar que para Arroyave o paraíso é inerentemente perdido, e a inocência carrega em si sua própria transgressão. É graças a ela que o homem é capaz de fixar seus próprios limites.

A reflexão, fala Arroyave, "menciona um representar-se a si mesmo ao que se denominou consciência. $\mathrm{O}$ ato pelo qual a consciência se representa a si mesma gera seu próprio poder e constitui sua própria independência" (2001, p.131).

Leyla Perrone-Moisés, em estudo sobre o olhar de Fernando Pessoa em cada um de seus pseudônimos, ao analisar a obra de Pessoa, o poeta, aponta para como a reflexão excessiva opõe-se ao sentir espontâneo, já que a consciência se auto-devora, e sua autovigilância é um meio de evitar o corpo (PERRONE-MOISES, 1988 p.329,332).

Arroyave (2001) evidencia que neste novo lugar ocupado, o espírito é orientado por regras, e a própria vontade aparece como um mecanismo de segurança, na medida em que se cria 
e manifesta com o objetivo de projetar a partir de si o desejado.

Com a inocência perdida, a graça transformada em afetação e a naturalidade em pose, caberia ao homem uma segunda entrada no paraíso, possível, segundo Kleist, através da "projeção do espírito humano [...] como aquele que se orienta pelo assombro insondável de um todo, cujo centro de gravidade é a força motriz da harmoniosa unidade entre homem e mundo" (ARROYAVE, 2001, p.134). Seria a superação do olhar "ataque armado de conceitos, carregado de intenções intelectivas ou de projeções psicológicas, olhar que separa, que cinde, que destrói” (PERRONE-MOISES, 1988 p.335), a remoção dos véus que separam o olhar do ver, o ver a parte do compreender o todo, o sujeito do objeto.

Mas para Kleist, este retorno não pode se dar a partir da negação da consciência, até porque isto equivaleria a desconhecer sua realidade histórica. Em lugar de excluí-la, ele propõe que se deva "assumir seu poder, perguntar pela sua natureza e limitações, para que se consiga ir além dela e orientar o homem a partir do sentimento" (ARROYAVE, 2001, p.130).

\section{Improvisação - o paraíso ainda não perdido}

O objeto a ser animado é uma extensão do corpo do ator. Este precisa conhecê-lo, testar possíveis centros de gravidade, saber como o objeto responde a impulsos gerados a partir de seu corpo, e como gera contra-impulsos. É importante deixar que imagens internas brotem ativamente e pesquisar como transmiti-las ao objeto, mas renunciando à subjetividade, que segundo Arroyave, "busca construir uma representação simples de si mesmo" (2001, p.131). Abrindo mão também das formas exclusivamente visíveis ou à imitação dos objetos do mundo, sem vaidade ou afetação.

A improvisação, primeiramente, é o momento de brincar, experimentar algo sobre si mesmo, o mundo e o objeto, sem se preocupar com o resultado. Mas ela pode ser também, e é importante que o seja, um momento de jogo, no qual, já sendo conhecido o objeto, algumas propostas são lançadas. A gestualidade permanece livre, mas buscando encontrar respostas, resolver os problemas de movimentação que naturalmente surgem. 
Esta busca por solução de problemas ainda não é um momento reflexivo. É com a experimentação de formas corporais, do peso, do equilíbrio que o ator vai descobrindo as formas orgânicas de movimento.

Como aponta Arroyave (2001), o momento oportuno para a reflexão se encontra depois do ato, pois quando se pensa no movimento, o fluxo espontâneo dos sentimentos é interrompido.

É nesta etapa que o ator vai construir o vocabulário de movimentos do boneco. Agora se faz necessário formular frases.

\section{Partitura de gestos - a transgressão da inocência}

A técnica da partitura, segundo Mônica Siedler, "funciona como um esquema objetivo e diretivo que se funda a partir de referências e de pontos de apoio para elaboração da complexa relação entre a dramaturgia do corpo e a cena" (2003, p.6).

Afirma, ainda, que "a partitura serve para fixar a forma da ação, ou seja, anima-la de detalhes, impulsos e contra-impulsos, sendo a sua elaboração importante para o ator, pois dela depende a sua precisão e, portanto, a qualidade de sua presença” (2003, p.23).

Depois de permitir o livre jogo na improvisação, os gestos são agora organizados. Para isso, é preciso classificar os estímulos em categorias significativas e funcionais, que configurarão os fragmentos iniciais, os quais posteriormente poderão ser reconstruídos em seqüências a partir de uma ampliação ou remoção para uma nova posição (BARBA, 1996, p.171). Com base em tal classificação, serão fixados limites à gestualidade, limites estes configuradores das regras dentro das quais o ator desenvolverá a movimentação. Transpondo para este contexto a idéia de Arroyave acerca da inocência, caberia afirmar que a improvisação, para que se sustente no tempo, carrega em si o momento reflexivo em que regras e limites serão configurados. 
Segundo Yoshi Oida, os limites estimulam a intensidade, e "o compromisso com um conjunto de regras liberta nossa criação e a faz atingir uma profundidade e um vigor que de outra forma seriam impossíveis" (2001, p.85). "Pode-se dizer que não há liberdade se não se paga o preço do ascetismo", este entendido como "limitação do eu", acrescentaria Jerzy Grotowski (BARBA, 1995, p.237).

Neste contexto é importante falar sobre a repetição. Barba ensina que os exercícios de cada ator "são repetidos como as palavras de uma língua estrangeira que se deseja aprender, de modo mecânico" (1995, p. 245), para mais tarde serem absorvidos e começarem a ter seu próprio desenvolvimento. De fato, a repetição é ato fundamental para que se atinja um estado em que a técnica é incorporada pelo ator, até o ponto em que ele passa a ter total controle sobre as regras criadas, de forma que elas se tornem tão naturais que desapareçam.

O olhar do poeta deforma o mundo para desvendar, perde-o para recupera-lo mais nítido. A perda do objeto pelo olhar, e pela palavra em que se tenta fixa-lo, é cisão irreparável no pensamento e no discurso, mas é apenas o preço provisório da reconquista poética. Fixado na fórmula poética, o objeto atinge sua máxima visibilidade. (PERRONE-MOISES, 1988, p.345).

A fixação da partitura não corresponde a um mito da técnica, tal como define Barba: “algo que se pode adquirir, possuir, e que pode dar ao ator o domínio consciente do seu corpo [...] cuja finalidade era obter conscientemente, por cálculo frio, algo quente e que obrigasse o espectador a acreditar com todos os seus sentidos” (1995, p.244). ao contrário, sua construção equivaleria a de uma escada equivaleria, assim, à construção de uma escada, a qual "representa plasticamente a ruptura de nível que torna possível a passagem de um modo de ser a outro" (ELIADE, 1996, p.46).

\section{Ascese ao paraíso}


Chega-se então ao ponto em que os limites deixam de sê-lo. As regras são desaprendidas, pois já conformam o percurso a ser seguido pelo ator, de forma que o sentimento passa a ser o centro de gravidade do ânimo, e a força unificadora do homem com o mundo, ou melhor, do ator com o objeto por ele animado.

Em contato com seu centro, o ator experimentará a realidade integral, a sacralidade, de forma a comunicar-se com o Céu, além de qualquer distinção entre sujeito e objeto, aquele que anima e aquele que é animado.

Instaura-se então um novo estado de consciência, ampliado, já que o ser está intensamente presente, sintonizado com a movimentação do boneco. A natureza deste novo estado se dá no instante, espontaneamente.

E graças à escada anteriormente construída, o trânsito entre a reflexão e a espontaneidade é livre. Assim como livre é o ator, que ao longo deste percurso aprendeu a desaprender.

\section{Referências}

ARROYAVE, Carlos Másmela. La conciencia y la gracia - Una interpretación filosófica de Sobre el teatro de marionetas de Henrich Kleist. Medellín: Editorial Universidad de Antioquia, 2001.

BARBA, Eugenio; SAVARESE, Íncola. A Arte Secreta do Ator - Dicionário de Antropologia Teatral. Campinas: Hucitec, 1995.

ELIADE, Mircea. Imagens e Símbolos - Ensaio sobre o simbolismo mágico-religioso. São Paulo: Martins Fontes, 1996, pp. 43-47.

JURKOWSKI, Henryck. Metamorphoses - La marionnette au XXe siècle. CharlevilleMézières: Éditions Institut International de la Marionnette, 2000.

MESCHKE, Michael. Uma estética para el teatro de títeres. Bizkaia: Arratia, [1988].

OIDA, Yoshi. O Ator Invisível. São Paulo: Beca, 2001.

PERRONE-MOISÉS, Leyla Maria. Pensar é estar doente dos olhos. In: NOVAES, Adauto (org.). O Olhar. São Paulo: Companhia das Letras, 1988. 
SIEDLER, Mônica. A Partitura Corporal e o Trabalho do Ator - Conceitos e Técnicas Aplicativas na Composição da Cena. Monografia - CEART/UDESC. Florianópolis, 2003.

DAPesquisa, Florianópolis, v.3 n.5, p.965-972, 2008. 